\title{
Sławomir Dorosiewicz
}

Collegium of Economic Analysis, Warsaw School of Economics, Poland

\section{CYCLICAL FLUCTUATIONS IN FREIGHT TRANSPORT IN SELECTED EUROPEAN UNION COUNTRIES. SYNCHRONIZATION, OR NOT?}

\begin{abstract}
Fluctuations of the economic activity in transport result from the operation of many factors of a demand and supply nature in all sectors of the economy. These factors determine both the common and specific characteristics of such fluctuations. The aim of this paper is not only to examine the morphological features of cyclical fluctuations on the transport market in Poland and selected countries of the European Union, but also the degree of their synchronization. The latter can be understood in the external context (between fluctuations in the transport production of various countries), but also in the internal one, where the subject of comparisons are fluctuations in transport and basic macroeconomic variables. The properties of business fluctuations will be examined by classical procedures for the separation of cyclical components and the detection of their turning points.

Keywords: freight transport, cyclical fluctuations
\end{abstract}

\section{Introduction}

For a long time, transport has been among the branches of the economy diagnosed from the point of view of the state and economic fluctuations. The research, which covers freight transport, was initiated in 1997 at the Motor Transport Institute. In 2004 in the Central Statistical Office, research on the economic situation in transport and storage was launched as part of the business climate survey in the services sector ${ }^{1}$. Such tests are usually conducted using the test method - the evaluations are based on information from a research questionnaire containing a set of questions

1 Economic Business Study: Methodological Notebook reviewed by the Methodological Commission of the Central Statistical Office. 
about qualitative changes in the situation of transport enterprises and their business environment. The detailed scope of research includes obtaining information on changes, financial situation of enterprises, their level of indebtedness, transport volumes and prices for transport services, the number of involved rolling stock, as well as subjectively perceived by transport companies barriers limiting their functioning and development. This allows to acquire information that is difficult to access or even impossible to obtain in a different way relatively quickly. As a consequence, such data also allow identification and forecasting of business fluctuations in the field of cargo transport. Encouraging results of empirical research show that the achieved values of business climate indicators in transport (and not only) are quite good in the process of formulating forecasts for "hard" characteristics of the transport sector, e.g. transport volumes and transport performance.

However, in this paper we will not deal with the issues of forecasting the economic situation, nor building models of this, limiting ourselves to the estimation of the basic characteristics of cyclical fluctuations of these hard variables describing the trucking sector. Looking somewhat forward, it can be concluded that the results of observations of fluctuations in the transport sector do not differ significantly from "stylized facts" observed in other branches of the economy.

In articles Adamowicz (2012) $)^{2}$, Gradzewicz (2010) ${ }^{3}$ and Skrzypczyński (2010) ${ }^{4}$, the fluctuations of basic values characterizing the state of the Polish economy were analyzed: gross domestic product, added value (in sectoral terms), individual and collective consumption, export, import, employment and average salary. This allowed not only to identify cycles of the most important macroeconomic characteristics of the Polish economy, but also the degree of its synchronization with the business cycle in the European Union countries, primarily with the countries of the euro area. All these and other papers, apart from updating the empirical results themselves, also present a certain "methodological canon" in the field of business cycle research. It is part of the identification of turning points of fluctuations, with the most probably known method of Bry-Boschan, or the use of various measures of similarity in order to capture the similarities and differences in the course of cyclic fluctuations.

The rather poor remark devoted to transport research to date seems inadequate to the importance of this sector for the whole economy, not only Poland. This work is intended as (very) modest attempt to change this state of affairs.

2 E. Adamowicz, S. Dudek, D. Pachucki, K. Walczyk, Wahania cykliczne w Polsce i strefie euro, SGH Warsaw School of Economics Publisher, Warsaw 2012.

3 M. Gradzewicz, J. Growiec, J. Hagemejer, P. Popowski, Cykl koniunkturalny w Polsce-wnioski z analizy spektralnej, Bank and Credit 2010, 41(5), p. 41-76.

4 P. Skrzypczyński, Metody spektralne w analizie cyklu koniunkturalnego gospodarki polskiej, National Bank of Poland, series: Materials and Studies, Paper No. 252, 2010. 


\section{Research methodology}

The research was carried out in the convention of the growth cycle (cycle of deviations ${ }^{5}$ ), where the cyclical components of variables characterizing the freight transport market and its economic environment are the subject of the analysis. The cyclical components themselves are not directly observed, and their separation requires the removal of the long-term path of changes, i.e. the trend. There is no single - canonical procedure - decomposition of time series, although the methods most commonly used in this area can be indicated. They have also been used in this work. Cyclic components of all series were estimated using the Christiano-Fitzgerald filter $^{6}$, eliminating both short-term fluctuations (accidental and seasonal fluctuations) as well as long-term fluctuations (trend). The frequency response of the filter covered periods from 2 to 10 years, corresponding to typical economic fluctuations. Both the trend and deviations from it may refer to the value of the variable itself $\left(y_{t}\right)$, or - more rarely - the rate of its change calculated according to the formula:

$$
r_{t}=\frac{y_{t+1}-y_{t}}{y_{t}}
$$

The position of turning points of cyclical components was estimated using the Bry-Boschan method ${ }^{7}$, dedicated to quarterly data. In the case of time series with relatively mild runs (and in the present considerations dealing with such series of cyclic components), turning points correspond to the local extremes of these series.

Regardless of whether the analyzed variable belonged to the "hard" or "soft" categories (results of questionnaire surveys), the course of action was as follows:

Time series ("raw data") $\longrightarrow$ Cyclic component $\longrightarrow$ Turning points.

Cyclic components illustrating fluctuations around the long-term trend allow distinguishing the growth and downward phases. The first one is the period of increased activity, characterized by a location above the trend line, the second one is accompanied by a slowdown in activity with the production volume below the trend line. Let us emphasize that the relegation and growth phases refer to cyclical components. Considering the fact that trends of observed values are increasing functions of time (this is the case for each variable discussed in this paper) and relatively small amplitudes of cyclic component variations, it can be concluded that in both phases the variable values are increasing, however, this increase is slowed down or accelerated compared to their long-term trends. These phases distribute the turning points (PZ): the bottom (D) corresponding to the transition from the declining phase to the growth phase and the upper one $(\mathrm{G})$ in which the change in economic activity runs in the opposite direction.

5 I. Mintz, Dating Postwar Business Cycles: Methods and Their Applications to Western Germany, 1950-1967, National Bureau of Economic Research, Cambridge 1969.

6 L.J. Christiano, T.J. Fitzgerald, The Band Pass Filter, International Economic Review 2003, 44(2), p. 435-465.

7 Cf. G. Bry, Ch. Boschan, Cyclical Analysis of Time Series, Technical Papers of NBER 1971, 20; D. Harding, A. Pagan, Dissecting the Cycle: A Methodological Investigation, Journal of Monetary Economics 2002, 49(2), p. 365-381. 
The identification of the turning points of the fluctuations, in turn, makes it possible to distinguish the growth phases (phases D-G, i.e. counting from the lower turning point to the next higher) and downward phases (G-D phases, counted from the upper turning point to the next lower turning point). This gives the possibility to determine the duration of said phases as well as full cycles defined as periods between successive lower or upper turning points (respectively D-G-D and G-D-G).

The simplest version of the classic fluctuation synchronization test method uses correlation coefficients between time series and time shifted copies of these series (so that the magnitude of the time shift, or the phase difference of these series). Unfortunately, the correlation coefficient itself is not a relatively resistant measure, remaining sensitive to atypical observations ("outliers"). Therefore, in order to examine the degree of similarity of fluctuations, and more precisely the similarities of the PZ positions of these fluctuations (and disregarding their amplitudes), additional measures of similarity were defined. They are not sensitive to changes in the amplitude of these fluctuations, they depend only on the location of their turning points.

For a given time series $\left(x_{t}\right)_{t \in T}$, we create a series $\left(x_{t}^{d}\right)_{t \in T}$ defined as follows: $x_{t}^{d}=1$ if the quarter $t$ is the upper turning point or $t$ belongs to the recovery phase (i.e. the nearest to the future turning point is the upper point). Otherwise, we accept $x_{t}^{d}=-1$. For such constructed series $\left(x_{t}^{d}\right)_{t \in T_{1}}\left(y_{t}^{d}\right)_{t \in T_{2}}$ for which $T:=T_{1} \cap T_{2} \neq \varnothing$ the following measures of similarity in the period can be defined in a natural way $T$ :

$$
\mu_{1}\left(x^{d}, y^{d}\right)=\Sigma_{t \in T} x_{t}^{d} y_{t}^{d} /|T|,
$$

(where $|T|$ is the number of elements of the set $T$ ) and

$$
\mu_{2}\left(x^{d}, y^{d}\right)=\Sigma_{t \in T}\left|x_{t}^{d}-y_{t}^{d}\right| /|T| \text {. }
$$

These measures can be used to check whether one of these series can be considered as ahead of the other. The basis for such analysis may be the comparison of the similarity of one series with the time-shifted copy of the other. A measure of such anticipation are therefore the numbers:

$$
\begin{aligned}
& r_{1}^{*}=\operatorname{argmax}\left(\mu_{1}\left(x^{d}, L^{r} y^{d}\right): r=-z, \ldots, z\right) \\
& r_{2}^{*}=\operatorname{argmin}\left(\mu_{2}\left(x^{d}, L^{r} y^{d}\right): r=-z, \ldots, z\right)
\end{aligned}
$$

where $z$ is an arbitrarily set number defining the scope of the series shifts considered $y^{d}, L^{r}$ means the operator of withdrawing over time the series by $r$ periods (i.e. $\left.\left(L^{r} y\right)_{t}=y_{t-r}\right)$. Note that if $r_{1}^{*}<0$, in the sense of measure $\mu_{1}$, the series $y^{d}$ precedes $x^{d}$ (and so the variations of the cyclic component $y$ of the series are preceded by fluctuations of such a component of the series $x$ ). Similarly, if $r_{1}^{*}>0$, in the sense of measure $\mu_{1}$, the series $x^{d}$ precedes $y^{d}$. From the point of view of the measure (1), and more precisely the criterion of its maximization, the simultaneous fluctuation can be said when $r_{1}^{*}=0$. The analogous interpretation can be given in size .

The determination of these values for the time series of the analyzed variables may provide some indication as to the degree of similarity of their cyclical fluctuations. Cyclical changes in transport performance in Poland. 
This part contains a summary of the results of empirical studies of cyclical fluctuations in transport production in Poland and some neighboring countries. The considerations are divided into two parts. In the first one, we discuss the results of research on fluctuations in cyclical variables characterizing the transport sector in Poland - the volume of transport and transport work. The second part is a short international review in the area under consideration. The calculations were made using the original procedures written in the $\mathrm{R}$ statistical packet.

In the case of Poland, the data used in the study came from the Central Statistical Office resources. Time series with a quarterly frequency included the period from the beginning of 2004 to the end of 2016 included the volume of transport and transport performance by road transport, broken down into domestic and international transport.

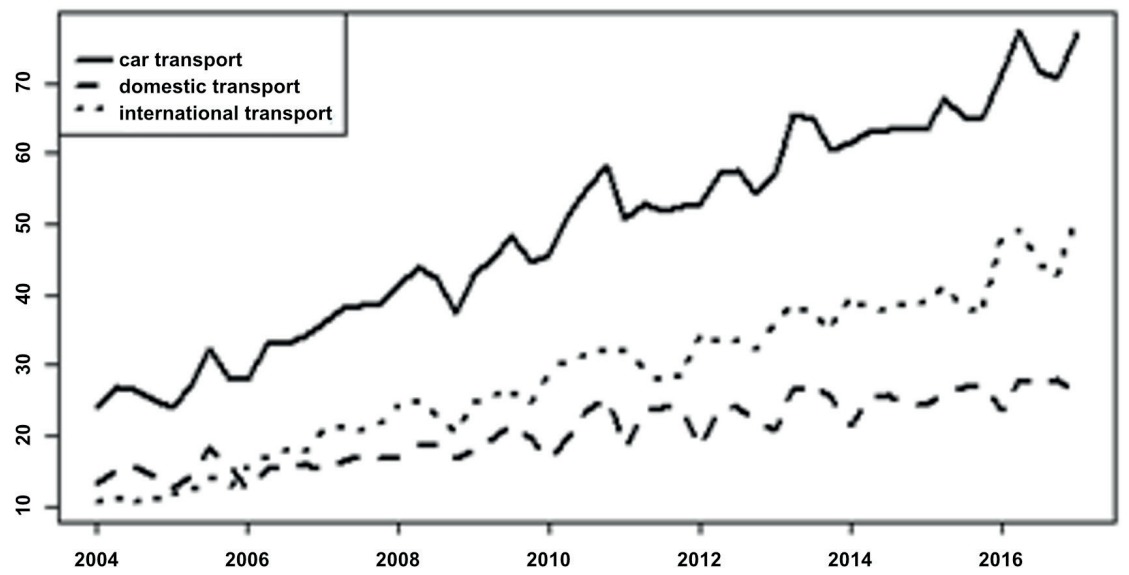

Figure 1. Transport performance in Poland, billion ton-km

Source: own elaboration based on: the CSO data

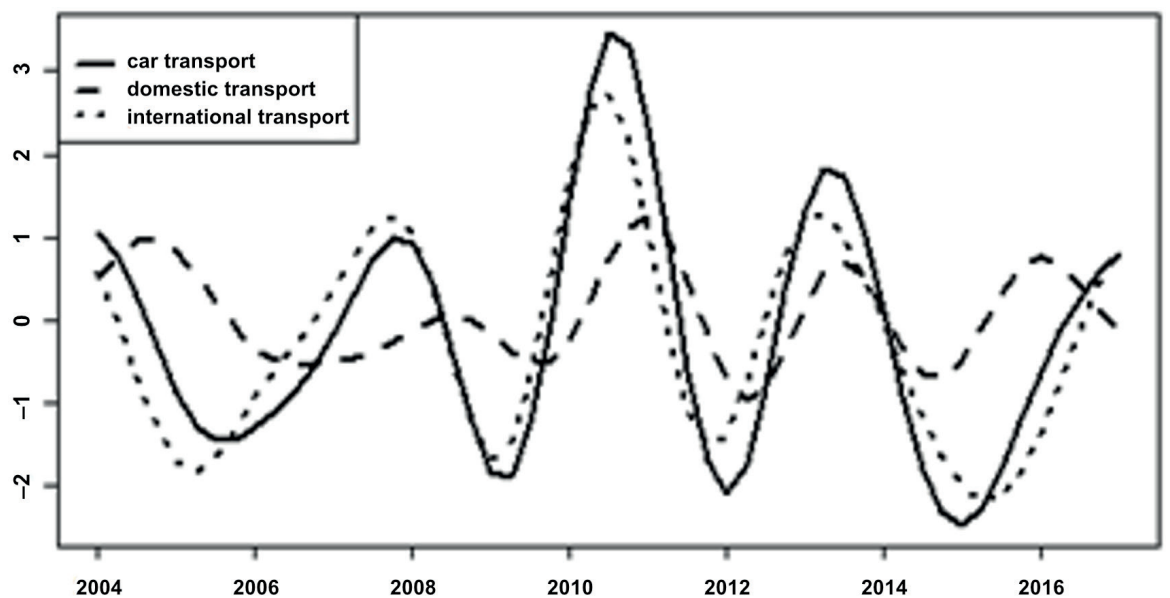

Figure 2. Cyclic components of transport performance, billion ton-km

Source: own calculations based on: the CSO data 


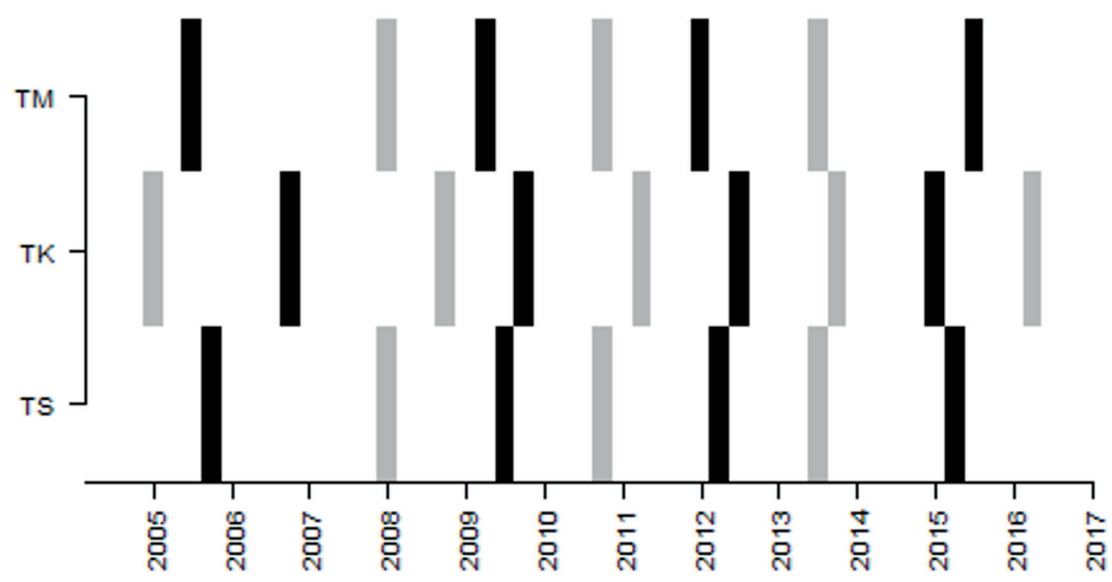

Figure 3. Position of turning points of cyclic components for transport performance Source: own calculations based on the CSO data

The volume of transport operations by road transport (TS) and its components relating to domestic (TK) and international (TM) transport were analyzed. Plots of raw time series of these variables are presented in Figure 1, while the course, estimated using Christiano-Fitzgerald filter, cyclical components of the mentioned series is shown in Figure 2. In all considered cases, these components are characterized by a typical "mild" course, which results in their the minimum and maximum values respectively determine the lower and upper turning points of the fluctuations.

In the case of the TS variable, the upper VP was identified in the periods 2007 (4), 2010 (3) and 2013 (2), while the lower ones in $2005(3)^{8}, 2009$ (2), 2012 (1) and 2015 (1), which gives 3 full DGD cycles (the same type of GDG) with an average duration of about 3.2 years. Cyclical fluctuations in national transport performance are characterized by a slightly higher frequency: upper PZ correspond to the following periods: 2004 (3), 2008 (2), 2011 (1), 2013 (3), 2016 (1), and lower periods - 2006 (3), 2009 (3), 2012 (2), 2014 (4), which translates into an average length of the DGD cycle equal to 2 years and 3 quarters. When it comes to international transport, the results are close to the TS variable. Minor differences can only be seen in the lower PZ variations. The average distance between neighboring lower VPs, and therefore the length of the DGD cycle, is equal to 3.3 years.

Cyclic components of TS, TK, TM change rates are even more volatile. This translates into an increase in the number of VPs and a reduction in the average time of a single cycle. Thus, the average duration of a full DGD cycle, i.e. the time interval between neighboring lower PZ fluctuations, in the case of total road transport and domestic transport performance, is about 2.3 years. Some surprise is the relatively long average such time - almost 4 years - in the case of international transport. In the latter case, we observe a rare case in which the growth phases last shorter than inheritance.

The comparison of PZ position is facilitated by drawing 3. The upper, blacklower turning points are marked with gray color. Their position in the case of the TS,

8 Quarter numbers are given in brackets. 
TM variables is very similar: the upper PZ are basically simultaneous, while the lower ones are basically - though not always - their counterparts for the TS. The location of turning points in domestic transport (TK) is somewhat less similar to the variables. The answer to the question whether the variations of cyclical components of variables have a pre-emptive character, possibly simultaneous or delayed, is essential. The location of PZ of the variables analyzed suggests that TS fluctuations are of a pre-emptive nature to TK, whereas TM - to the other variables.

Of course, we rarely deal with a situation where always (of course, we mean only the observed time range) the turning points of one size precede their counterparts in the other. Usually this is not the case and you can only talk about the average amount of advance of one size by the other, agreeing with the situation that in some periods the position of $\mathrm{PZ}$ of the compared sizes will be reversed.

The basis of the diagnostics will be the average of advance (3) and (4) turning points of variables in relation to the turning points of the remaining quantities. Table 1 gives the values of these leads for all currently analyzed variable pairs. Within the meaning of both criteria - maximization of the value of measure (1) and minimization (2) - turning points of variations of the TS variable precede their counterparts in the TK variable by about 1 quarter, and TM fluctuations precede TS fluctuations by about 2 quarters. However, these criteria give different indications as to the fluctuation of the TK and TM variables. Taking into account the first criterion, TM fluctuations are ahead of the TK by about 3 quarters; the second criterion indicates, however, the "average" simultaneity of these fluctuations.

The desirable property, with no small precondition for synchronization of fluctuations, is the consistency of the times of the growth and declining phases of the compared variables. Meeting this requirement leads to (smaller or larger) compliance of the number of turning points of indicators and reference values, which allows to reduce the risk of false signals of a change in the upward or downward phase.

Table 1. Values of time shifts for which the highest similarity of cyclic fluctuations of successive pairs of compared variables (TS, TK, TM) was obtained. Each of the elements of the table contains, in turn, the offset values (3) and (4) calculated for the respective pair of variables

\begin{tabular}{|c|c|c|c|}
\cline { 2 - 4 } \multicolumn{1}{c|}{} & TS & TK & TM \\
\hline TS & - & $-1,-1$ & 2.2 \\
\hline TK & 1.1 & - & 3.0 \\
\hline TM & $-2,-2$ & -3.0 & - \\
\hline
\end{tabular}

Source: own calculations based on: the CSO data

It is worth adding that Figure 3 is easily "expanded" by including information on the location of key, "hard" turning points, characteristics of the economy and transport sector (primarily GDP, exchanges with abroad, value added transport) and "soft" business climate indicators. Such a process allows to conclude that in the first part of the analyzed period (from 2004), more or less until 2011, the location of turning points of these variables is more or less regular. Turning points of business climate indicators in transport were concurrent or slightly delayed in relation to "hard" variables. As a result of the crisis which began in 2008, the synchronization of cyclical fluctuations became visible. This is clearly visible 
from 2012. From that moment, the leading nature of business climate indicators is quite clearly visible in relation to the majority of "hard" variables.

\section{A brief international review}

Cyclical fluctuations of the economic situation in rail and road transport were observed on the basis of changes in the volume of transport performance carried out. The starting point was the data on the volume of transport performance for selected countries with different seniority in the European Union taken from the Eurostat database: Belgium (BE), Germany (DE), Spain (ES), France (FR), Italy (IT), The Netherlands (NL), Austria (AT) (for these countries the time span of the data covered the years 1999-2016); Czech Republic (CZ, period 2000 (1) - 2016 (4)), Hungary (HU, 2001 (1) - 2016 (4)) and Poland (PL, 2004 (4) - 2016 (4)).

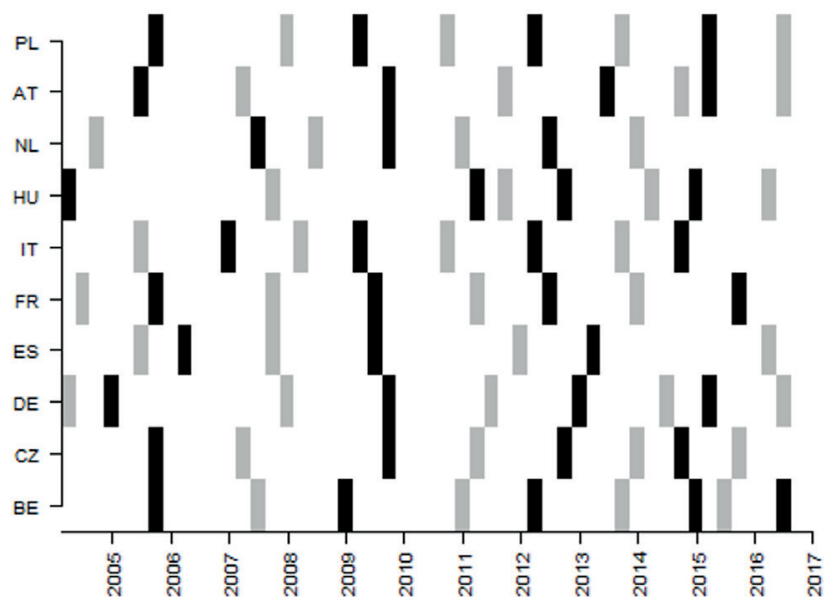

Figure 4. Location of turning points in transport performance in selected EU countries Source: own calculations based on: data from the Eurostat database

Table 2. Basic characteristics of cyclical fluctuations in transport performance in selected countries

\begin{tabular}{|c|c|c|}
\hline Country & The average time of the growth phase & The average time of the decreasing phase \\
\hline BE & 1.44 & 1.9 \\
\hline CZ & 1.4 & 1.81 \\
\hline DE & 1.7 & 1.6 \\
\hline ES & 1.9 & 1.35 \\
\hline FR & 1.5 & 1.42 \\
\hline IT & 1.45 & 1.17 \\
\hline HU & 1.69 & 1.75 \\
\hline NL & 1.2 & 1.65 \\
\hline AT & 1.38 & 1.38 \\
\hline PL & 1.62 & 1.42 \\
\hline
\end{tabular}

Source: own calculations based on: data from the Eurostat database 
Table 3. Values of time shifts (3), (4) between cyclical fluctuations in transport performance in Poland and in selected EU countries

\begin{tabular}{|l|c|c|c|c|c|c|c|c|}
\cline { 2 - 9 } \multicolumn{1}{c|}{} & BE & DE & ES & FR & IT & HU & NL & AT \\
\hline measure (1) & 0.26 & 0.36 & -0.03 & 0.20 & -0.13 & 0.31 & 0.26 & -0.23 \\
\hline shift 3) & 2 & 3 & -2 & -2 & -2 & 0 & 0 & 3 \\
\hline measure (2) & 0.16 & 0.15 & 0.20 & 0.17 & 0.21 & 0.16 & 0.16 & 0.22 \\
\hline shift (4) & 2 & 3 & -2 & -2 & 1 & 0 & 0 & 3 \\
\hline
\end{tabular}

Source: own calculations based on: data from the Eurostat database

The average lengths of growth and decreasing phases, estimated for the countries studied, fluctuate within the same limits, namely 1.20-1.90. They do not differ significantly from the results obtained for Poland. The longest average duration of decreasing phases is recorded for Spain. In turn, in terms of growth phases, the longest average is observed in the transport sector of Belgium and the Czech Republic, and the shortest in Italy (see Table 2).

In most cases we observe similar numbers of PZ. Their position is shown in Figure 4. Their distribution is basically fairly regular, although a small increase in their occurrence (and as a consequence, a reduction in the average time of decreasing and growth phases) has been recorded since 2010, that is, the time following the recent global crisis. Both in the period preceding the crisis and later, we observe a relatively good PD synchronization. Period of 2007-mid-2008 corresponds to the end of the acceleration phase (upper PZ); period 2009-2010 is the end of the decreasing phase and the beginning of acceleration. At the end of 2011, the next phase of the slowdown begins, the end of which falls on the next year. The next transition from the acceleration phase to the slowdown phase takes place at the turn of 2013 and 2014. Period of 2015 until the beginning of 2017 is generally the acceleration time. Of course, the inflow of subsequent data may cause the need to modify the position of the last VPs to change the time limits of cycle phases.

The extreme values (respectively maximum and minimum) of the similarity measures (1) and (2) between the transport cycles of Poland and the EU Member States surveyed are included in Table 3. Cyclic fluctuations in transport performance in Poland usually precede such fluctuations in Spain and France. These overtures are not significant. Simultaneous character seems to have fluctuations in transport performance in the Netherlands and Hungary, while delays can be observed in the case of transport work of Belgium, Austria and Denmark. The comparison results in the case of the Czech Republic do not seem to be stable enough and were not quoted for this reason.

\section{Conclusions}

The studies of the PZ position of cyclical fluctuations play a significant role in the creation, verification, or calibration of business cycle models as well as in the forecasting process. By their nature, they also play a fundamental role in the construction of leading or possibly parallel business climate indicators. 
The evaluation of the degree of synchronization of fluctuations is one of the basic of all these analyzes. The presented results (confirmed also by estimations of the maxima of spectral density functions) show that cyclic fluctuations in transport performance do not differ in their characteristics from the typical ranges observed in other branches of the economy. However, when it comes to the degree of synchronization of cyclical fluctuations in transport performance in different countries, it can be described as moderate. This is evidenced by the values of both similarity indicators. Also, phase shifts estimated on the basis of spectral analysis do not seem (so far?) To provide a clear description that could be - without much fluctuation - cited in the context of "empirical evidence" of strong synchronization. The length of the time series, including the number of quarterly data for Poland, additionally require treating the results with a proper dose of caution.

\section{References}

Adamowicz E., Dudek S., Pachucki D., Walczyk K., Wahania cykliczne w Polsce $i$ strefie euro, SGH Warsaw School of Economis, Warsaw 2012.

Badania Koniunktury Gospodarczej: Zeszyt metodologiczny zaopiniowany przez Komisję Metodologiczną GUS, Central Statistical Office Publisher, Department of Enterprises, 2017, https:// stat.gov.pl/files/.../badanie_koniunktury_gospodarczej_wyd_luty_2017.pdf.

Bry G., Boschan Ch., Cyclical Analysis of Time Series, Technical Papers of NBER 1971, 20.

Christiano L.J., Fitzgerald T.J., The Band Pass Filter, International Economic Review 2003, 44(2).

Dorosiewicz S., Koniunktura w transporcie. Metodyka badań, wyniki, modele, ITS Publisher, Warsaw 2013.

Gradzewicz M., Growiec J., Hagemejer J., Popowski P., Cykl koniunkturalny w Polsce - wnioski $z$ analizy spektralnej, Bank and Credit 2010, 41(5).

Harding D., Pagan A., Dissecting the Cycle: A Methodological Investigation, Journal of Monetary Economics 2002, 49(2).

Mintz I., Dating Postwar Business Cycles: Methods and Their Applications to Western Germany, 1950-1967, National Bureau of Economic Research, Cambridge 1969.

Skrzypczyński P., Metody spektralne w analizie cyklu koniunkturalnego gospodarki polskiej, National Bank of Poland, series: Materials and Studies, Paper No. 252, 2010.

\section{Corresponding author}

Sławomir Dorosiewicz can be contacted at: doro@sgh.waw.pl 